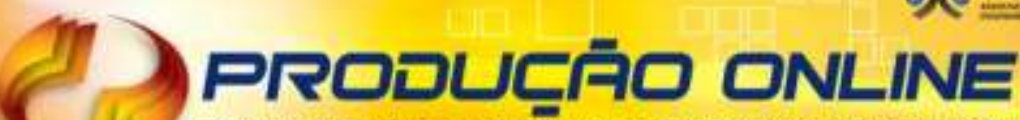 REVISTA CIENTIFICA ELETRÖNICA DE ENGENHARIA DE PRODUÇAO ISSN 1676-190
}

\section{POR QUE ELES DESISTEM? ANÁLISE DA EVASÃO NO CURSO DE ENGENHARIA DE PRODUÇÃO, UFES, CAMPUS SÃO MATEUS}

\section{WHY DO THEY GIVE UP? EVASION ANALYSIS IN THE PRODUCTION ENGINEERING COURSE, UFES, CAMPUS SÃO MATEUS}

\author{
Marielce de Cássia Ribeiro Tosta* E-mail: marielce.tosta@ufes.br \\ Jose Ricardo Fornaciari* E-mail: ricardofornaciari@hotmail.com \\ Leonardo Caetano Abreu*E-mail: leonardocaetanoabreu@gmail.com \\ *Universidade Federal do Espírito Santo (UFES), São Mateus, ES.
}

\begin{abstract}
Resumo: Nos últimos anos o sistema brasileiro de educação superior expandiu a oferta de cursos de engenharia. Apesar desta expansão tem-se percebido o aumento no número de evasão dos alunos. De maneira a contribuir com a análise das causas desta evasão o presente trabalho teve como objetivo definir o perfil do curso de Engenharia de Produção, São Mateus. Verificou-se que o curso possui predomínio de alunos: i) residentes no próprio Estado e cidade; ii) do sexo masculino; iii) idade entre 18 e 25 anos e; iv) melhores coeficientes de rendimento nos últimos períodos. Tanto à relação entre alunos diplomados por alunos evadidos quanto à taxa de retenção do curso indicam a necessidade de melhorar a qualidade do curso de modo a viabilizar a finalização em menor tempo. Analisando a evasão verificou-se que a mesma ocorreu em 144 de um total de 441 alunos matriculados, sendo a desistência a principal razão da evasão (77). Foi analisado ainda o grau de retenção das disciplinas básicas, sendo esta entre $40 \%$ a $80 \%$ em disciplinas do primeiro e segundo período. De acordo com os resultados há necessidade da coordenação do curso em acompanhar cuidadosamente os primeiros períodos bem como promover atividades de nivelamento e monitorias.
\end{abstract}

Palavras-chave: Evasão. Retenção. Educação Superior. Engenharia de Produção. Perfil do curso.

Abstract: The Brazilian higher education system has expanded the offer of engineering courses in recent years. Despite of this expansion has been perceived the student evasion number increase. In order to evaluate the evasion causes this work aimed to define the São Mateus Production Engineering course profile. It was verified predomination of students: i) resident in the own State and city; ii) males; iii) aged between 18 and 25 years old and; iv) which had the best coefficients in the last periods. Students graduated by students evaded rate and the course retention rate both indicate the need to improve course quality in order to achieve the course completion in a shorter time. Evasion analysis verified that 144 of a total of 441 students evaded; with abandonment being evasion main reason (77). The degree of basic subjects' retention was analyzed; it was $40 \%$ to $80 \%$ in first and second period subjects. According to the results, there is a need for course coordination monitor carefully the first periods as well as to promote leveling activities and tutorials.

Keywords: Evasion. Retention. Higher Education. Production Engineering. Course Profile.

\section{INTRODUÇÃo}

O sistema brasileiro de educação superior passou por um processo de expansão acelerado nos últimos anos. Segundo Oliveira et. al. (2013), os cursos de Engenharia obtiveram crescimento significativo, sendo que o número de 
profissionais egressos destes cursos praticamente quadruplicou nos últimos anos. A média anual de crescimento do número de concluintes saltou de aproximadamente $5 \%$ na década de 1990 para cerca de $10 \%$ nos últimos 10 anos.

No entanto, relacionada a essa expansão uma questão vem se destacando: a evasão. Segundo Silva Filho et. al. (2007) a taxa de evasão no primeiro ano de curso é duas a três vezes maiores do que a dos anos seguintes. A preocupação com a evasão escolar no ensino superior tem sido tema de instituições superiores em todo âmbito educacional, tanto público quanto privado. Segundo Adachi (2009) quando os alunos ingressam nos cursos representam ativos, mas ao desistir ou optar pela mudança para outro curso ou instituição, representam perda de investimentos. Assim sendo, torna-se essencial para o bom desenvolvimento dos cursos identificarem essas gaps em suas estruturas, a fim de adquirirem condições de agir consistentemente com o objetivo de minorar os problemas a ele afeitos.

Silva (2013) diz que a evasão do ensino superior brasileiro ainda é um fenômeno pouco explorado pela literatura acadêmica. A falta de trabalhos e de atenção das próprias instituições de educação superior (IES) brasileiras torna o estudo e a busca das causas e desenvolvimentos de programas que combatam essa evasão prejudicada. Isto porque há uma dificuldade no monitoramento dos alunos evadidos. Lobo (2012) ressalta que definir e medir a evasão são muito difíceis, pois há várias padronizações quanto ao tema, sendo evasões de: cursos, das instituições (IES) e do sistema.

Para Ferreira et. al. (2001) um dos principais fatores que levam a dificuldades dos alunos se inserirem no meio acadêmico está relacionado à quebra de vícios e costumes presentes até 0 ensino médio. O autor destaca a dificuldade no engajamento dos alunos nos novos parâmetros, em ambiente bem menos paternalista e muito mais autônomo, como por exemplo, a relação com os professores, que é bem menos estreita que as relações do ensino médio. Além disso, têm-se ainda os métodos de estudos, a gestão do tempo, bases do conhecimento para o curso, autoconfiança dentre outros fatores que são fundamentais para o entendimento da adaptação do estudante.

Gomes et. al. (2010) destaca ainda que a evasão possa ocorrer por motivos variados: dificuldades financeiras, falta de vocação, descontentamento acerca do método didático-pedagógico da instituição, motivos pessoais, como doença grave ou 
morte, transferência de domicílio. Outros autores como Silva Filho et. al. (2007) e Gaioso (2006) discutem que fatores socioeconômicos são muito importantes nesta análise e ressaltam que há diferença entre o estudante desistir da faculdade ou não ter acesso à mesma devido a esta questão.

Outro fator apresentado para explicar a crescente evasão está relacionado ao aumento do número de equívocos que os ingressantes têm no momento que encolhem os cursos onde muitas vezes tem-se visão deturpada do mercado de trabalho e da profissão e ao entrar na Universidade ficam decepcionados e desmotivados, levando a evasão prematura, como aponta Gomes et. al. (2010).

Segundo Martins et. al. (2014) a evasão nos cursos de engenharia refere-se à deficiência na formação básica, bem como o domínio da língua pátria e hábitos de estudo e pesquisa. Os autores ressaltam ainda que as dificuldades do núcleo básico dos cursos se devem a falta de conhecimento de física e matemática o que aumenta a evasão e a retenção em média de 50\% para cursos de engenharia no Brasil.

Gilioli (2016) corrobora a importância das disciplinas básicas na análise de evasão e retenção destacando que as reprovações em disciplinas nos quatro primeiros semestres dos cursos nas décadas de 1980 e 1990 foram fatores essenciais para a evasão nos mesmos. Pereira et. al. (2016) analisaram as principais características dos alunos retidos nos cursos presenciais da Universidade Federal do Espírito Santo e determinaram que o número de reprovações e o coeficiente de rendimento acumulado é o componente preponderante na compreensão do fenômeno da retenção, assim como no processo de evasão.

Assim sendo, torna-se de extrema relevância conhecer o perfil dos alunos de um curso para buscar entender as suas particularidades e saber agir de maneira corretiva de forma mais adequada frente aos possíveis problemas, dentre eles a própria evasão. Destarte o objetivo deste trabalho foi definir o perfil do curso de Engenharia de Produção do campus São Mateus da Universidade Federal do Espírito Santo. Especificamente buscou-se mapear as características dos estudantes quanto aos aspectos socioeconômicos, dados de: ingresso, concluintes, retenção e evasão no curso. 


\section{DADOS GERAIS DO CURSO DE ENGENHARIA DE PRODUÇÃO NO BRASIL}

De acordo com o Instituto Nacional de Estudos e Pesquisas Educacionais Anísio Teixeira (INEP) e Conselho Federal de Engenharia e Agronomia (CONFEA) (2010) o curso de Engenharia de Produção iniciou-se no Brasil na metade do século XX, na Escola Politécnica da Universidade de São Paulo (Poli/USP). A graduação em Engenharia de Produção, por sua vez, é criada somente em 27 de novembro de 1970 sendo desvinculada da área da engenharia mecânica. Em 1990 havia 19 cursos no país sendo estes nos estados de São Paulo (8), Rio de Janeiro (7), Santa Catarina (3) e Rio Grande do Sul (1).

Em 1996 foi aprovada a Lei no 9.394 que "estabelece as diretrizes e bases da educação nacional". Esta lei facilitou as condições para criação de novas instituições de educação superior (IES) e de novos cursos de graduação, principalmente na área da Engenharia (OLIVEIRA et. al., 2005). A partir deste ano houve significativa expansão no número de cursos de Engenharia de Produção. Em 2008 havia 197 cursos já em 2015 este número foi para 708 cursos, crescimento de $360 \%$ no período (Gráfico 1).

Segundo INEP/CONFEA (2010) três fatores, podem explicar este aumento no número de cursos. O primeiro deles está relacionado ao próprio desenvolvimento do mercado que exige maior conhecimento tecnológico e sistêmico no desenvolvimento de suas atividades. Outra questão relevante foi à alteração no foco do curso que deixou de ter "ênfases" e passou a ser "pleno". E por fim, é importante ressaltar a alteração da lei da LDB de 1996 que possibilitou a criação de novos cursos principalmente em instituições privadas que passaram de 148 cursos em 2008 para 582 cursos em 2015 (INEP, 2016). O estado do Espírito Santo em 2016 possuía 11 instituições que oferecem o curso de Engenharia de Produção (QUADRO 1); sendo 3 públicas e 8 privadas. 
Gráfico 1 - Crescimento no número de cursos (Total, Privado e Público) de Engenharia de Produção (2008 a 2015)

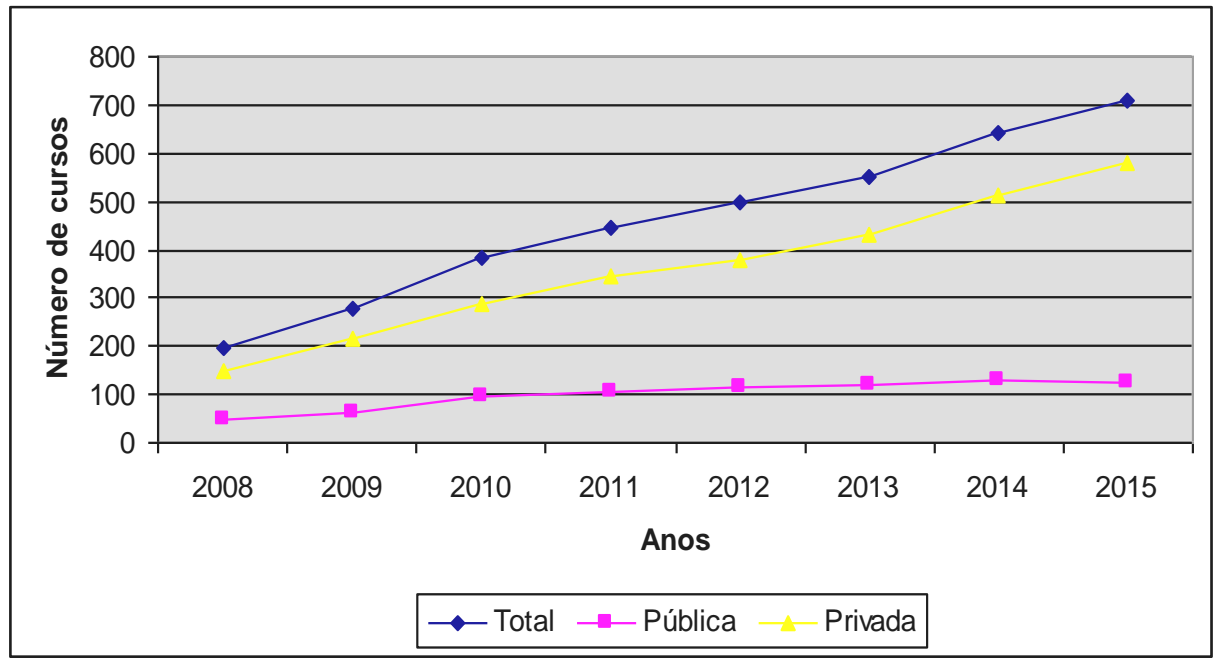

Fonte: INEP (2016)

Quadro 1 - Instituições com o curso de Engenharia de Produção no Espírito Santo

Instituição

Instituto Federal do Espírito Santo

Faculdades Integradas de Aracruz

Faculdade Vale do Cricaré

Faculdade Multivix

Faculdade Pitágoras

Faculdade Católica Salesiana do Espírito Santo

Centro Universitário São Camilo

Faculdade do Centro Leste

Universidade Federal do Espírito Santo- Ceunes

Universidade Federal do Espírito Santo - Goiabeiras

Universidade Vila Velha

Fonte: Elaborado pelo autor (2016)

O aumento no número de cursos de Engenharia de Produção está relacionado à procura pelo curso e a demanda do mercado. De 2011 a 2015 a relação média de candidato vaga no País foi de 2,68. No entanto, o número de ingressos foi em média de $70 \%$ das vagas (TABELA 1). Essas diferenças entre o número de vagas oferecidas, candidatos inscritos e ingressos podem ser explicadas pelo elevado número de vagas ofertadas pelas instituições particulares e pelo fato
Sigla/Abreviação

IFES

FAACZ

FVC

Multivix

Pitágoras

Salesiana

São Camilo

UCL

UFES - CEUNES

UFES - GOIABEIRAS

UVV 
de um mesmo candidato poder estar inscrito em mais de um processo seletivo no ano. De acordo com INEP/CONFEA (2010) a relação ingresso com número de vagas apresentou valores menores em anos anteriores sendo ocupado em média $60 \%$ das vagas na década dos anos 2000.

Tabela 1 - Número de vagas oferecidas, candidatos inscritos e ingressos no curso de Engenharia de Produção (2011 a 2015)

\begin{tabular}{|c|c|c|c|c|c|c|c|}
\hline \multirow{2}{*}{} & \multicolumn{7}{|c|}{ Seleção para Vagas Novas } \\
\cline { 2 - 7 } \multicolumn{1}{c|}{} & \multicolumn{3}{|c|}{ Vagas Oferecidas } & \multicolumn{3}{c|}{ Candidatos Inscritos } & \multirow{2}{*}{ Ingressos } \\
\cline { 2 - 7 } \multicolumn{1}{c|}{ Total } & Pública & Privada & Total & Pública & Privada & \\
\hline $\mathbf{2 0 1 5}$ & 124094 & 7653 & 116441 & 278940 & 135577 & 143363 & 60958 \\
\hline $\mathbf{2 0 1 4}$ & 104745 & 7407 & 97338 & 255937 & 127486 & 128451 & 66499 \\
\hline $\mathbf{2 0 1 3}$ & 80231 & 6359 & 73872 & 241206 & 121320 & 119886 & 58708 \\
\hline $\mathbf{2 0 1 2}$ & 71268 & 6270 & 64998 & 212220 & 102179 & 110041 & 56944 \\
\hline $\mathbf{2 0 1 1}$ & 63111 & 5621 & 57490 & 173870 & 79831 & 94039 & 54039 \\
\hline
\end{tabular}

Fonte: INEP (2016)

Outro ponto importante a ser apresentando está relacionado à relação entre o número de alunos concluintes e ingressantes no curso. Entre 2004 e 2007 esta relação ficou entre 60\% a 70\% (INEP/CONFEA, 2010). No período entre 2010 e 2013 esta relação entre concluintes e ingressantes se manteve em média de 70\%. No entanto, este valor reduziu significativamente nos anos de 2014 (41\%) e 2015 (27\%) (TABELA 2).

Tabela 2 - Relação entre número de alunos concluintes e alunos ingressantes (2010 a 2015)

\begin{tabular}{|c|c|c|c|c|}
\hline Ano & Concluintes & Ano & Ingressantes & Percentual Concluintes/Ingressantes \\
\hline $\mathbf{2 0 1 5}$ & 14830 & $\mathbf{2 0 1 1}$ & 54039 & 0,27 \\
\hline $\mathbf{2 0 1 4}$ & 12426 & $\mathbf{2 0 1 0}$ & 29949 & 0,41 \\
\hline $\mathbf{2 0 1 3}$ & 12200 & $\mathbf{2 0 0 9}$ & 18602 & 0,66 \\
\hline $\mathbf{2 0 1 2}$ & 10970 & $\mathbf{2 0 0 8}$ & 15360 & 0,71 \\
\hline $\mathbf{2 0 1 1}$ & 8322 & $\mathbf{2 0 0 7}$ & 11762 & 0,71 \\
\hline $\mathbf{2 0 1 0}$ & 6958 & $\mathbf{2 0 0 6}$ & 9346 & 0,74 \\
\hline
\end{tabular}

Fonte: INEP (2016)

Para finalizar estes dados gerais do curso de Engenharia de Produção no Brasil apresenta-se a evolução do número de alunos matriculados de 2011 a 2015 e sua relação com o número total de matrículas trancadas e alunos evadidos (GRÁFICO 2). 
Gráfico 2 - Número de alunos matriculados, evadidos e matrículas trancadas no curso de Engenharia de Produção, Brasil (2011 a 2015)

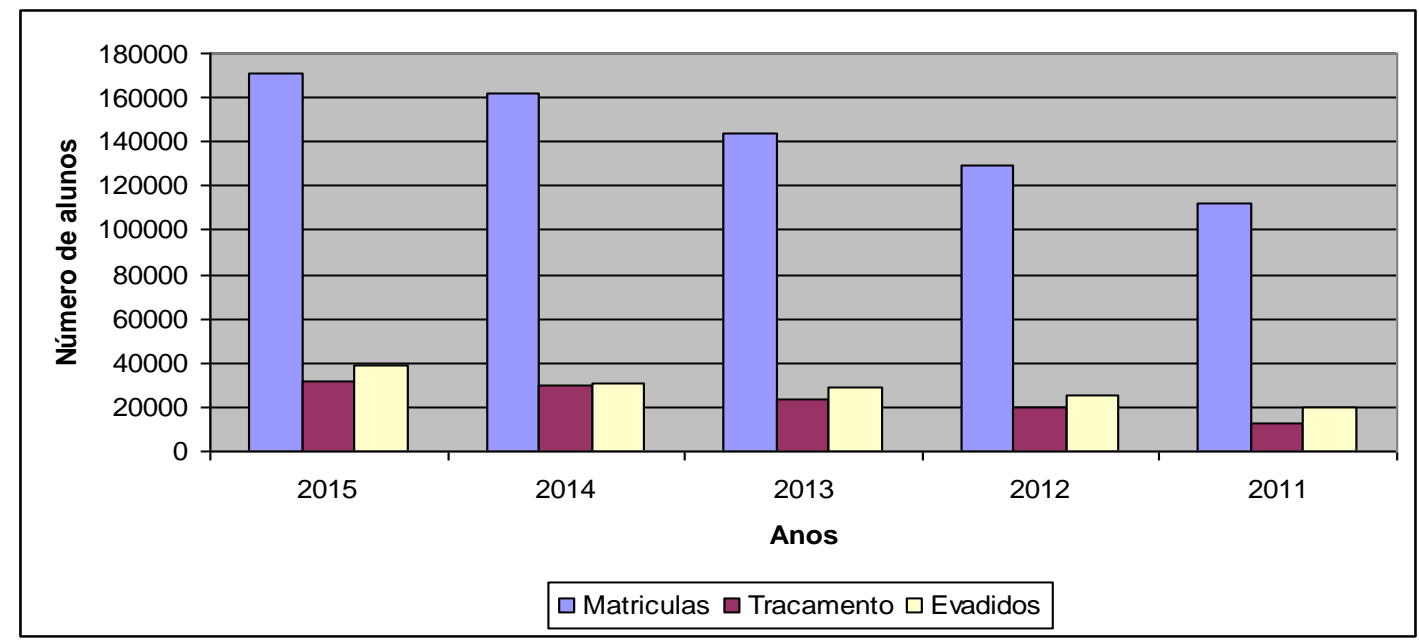

Fonte: INEP (2016)

O número de alunos matriculados aumentou em $35 \%$ passando de 111.848 em 2011 para 170.587 alunos em 2015. Já o número de matrículas trancadas e alunos evadidos em relação ao número de matrículas total passaram de 12\% e 18\% em 2011 para $19 \%$ e $23 \%$ em 2015 , respectivamente. Além disso, cabe ressaltar, que $90 \%$ dos trancamentos e do número de alunos evadidos estão relacionados a alunos matriculados em instituições particulares. Assim sendo, a relação entre o número de alunos evadidos com o número de alunos matriculados em instituições públicas no Brasil está em torno de 10\% ao ano (INEP, 2016).

\section{OBTENÇÃO E TRATAMENTO DOS DADOS}

Para análise do perfil dos alunos do curso de Engenharia de Produção da Universidade Federal do Espírito Santo (UFES) no Centro Universitário Norte do Espírito Santo (CEUNES) foi utilizado banco de dados obtidos junto à coordenação do curso para o período compreendido entre 2006 e 2016. Os dados levantados foram: quanto à data de nascimento, sexo, período, ano e forma de ingresso, período, ano e forma de evasão, período atual, carga horário e créditos do currículo realizado pelo aluno, coeficiente de rendimento, número de matrícula em disciplinas e número de reprovações em disciplinas por semestre letivo.

Para organizar e analisar os dados utilizou-se a estatística descritiva, cujo objetivo básico é o de sintetizar uma série de valores de mesma natureza, 
permitindo dessa forma que se tenha uma visão global da variação desses valores, organiza e descreve os dados de três maneiras: por meio de tabelas, de gráficos e de medidas. As medidas de estatística descritiva permitem sintetizar os dados da população ou da amostra através de um só valor por meio de medidas de tendência central e medidas de dispersão.

As medidas da tendência central são indicadores que permitem que se tenha uma primeira idéia ou resumo, do modo como se distribuem os dados de uma experiência, informando sobre o valor (ou valores) da variável aleatória, sendo: a média, a moda e a mediana. Já as medidas de dispersão traduzem a variação de um conjunto de dados em torno da média, ou seja, da maior ou menor variabilidade dos resultados obtidos. Permitem identificar até que ponto os resultados se concentram ou não ao redor da tendência central de um conjunto de observações. Incluem, entre outras, o desvio absoluto médio, a variância e o desvio padrão, cada uma expressando diferentes formas de quantificar a tendência que os resultados de uma experiência aleatória têm para se concentrarem em determinados valores. Quanto maior for à dispersão, menor é a concentração e vice versa.

\section{CONTEXTO E ARTICULAÇÃO DO PROJETO PEDAGÓGICO DO CURSO DE ENGENHARIA DE PRODUÇÃO EM SÃO MATEUS}

Foi aprovado em novembro de 2005 o Plano de Expansão e Consolidação da Interiorização Presencial da Universidade Federal do Espírito Santo (UFES) com a criação do Centro Universitário Norte do Espírito Santo (CEUNES). Este foi criado com objetivo de elaborar uma base permanente de ensino público superior no interior do Estado.

Em 2016 o CEUNES contava com uma Biblioteca setorial dotado com acervo de 27.311 exemplares, Restaurante Universitário, 23 prédios prontos, contendo rede elétrica e digital de transmissão de dados, e 01 em construção, além de obras de infra-estrutura. Contemplam dezessete cursos de graduação, quatro cursos de pósgraduação e sete departamentos entre eles 0 de Engenharias e Tecnologia (DETEC) onde está inserido o curso de Engenharia de Produção.

O curso tem como missão gerar avanços científicos e tecnológicos, por meio do ensino, da pesquisa e da extensão, produzindo e socializando conhecimento nas 
diferentes áreas da Engenharia de Produção para formar cidadãos com capacidade de implementar soluções que promovam o desenvolvimento sustentável regional. Nessa perspectiva, o seu objetivo geral de acordo com o Projeto Político Pedagógico é a formação profissional do Engenheiro de Produção, além do domínio operacional de técnicas de trabalho interpostos em produção, a compreensão global do processo produtivo, com a apreensão do saber tecnológico e do conhecimento que dá forma ao saber técnico e ao ato de fazer, com a valorização da cultura do trabalho e com a mobilização dos valores necessários à tomada de decisões profissionais e ao monitoramento do seu próprio desempenho profissional, em busca da segurança, da economia, do belo e da perfeição.

No que diz respeito à grade curricular o curso possui carga horária de 4035 horas das quais 3300 horas em disciplinas obrigatórias, 165 em disciplinas optativas, 120 em Atividades Complementares, 300 em estágio supervisionado e 150 horas para o Trabalho de Conclusão de Curso organizadas em 10 períodos semestrais.

De acordo com Censo Sócio Econômico realizado pela Comissão Coordenadora do Vestibular (CCV) junto aos alunos matriculados em média dos últimos anos aproximadamente $86 \%$ foram do próprio Estado do Espírito Santo, 9,5\% são provenientes de Minas Gerais, 4\% da Bahia e o restante de outros Estados. No vestibular de 2016, o percentual de alunos matriculados que possuem residência em São Mateus foi de $50,3 \%$ e do Estado foram no total $80,1 \%$. Para o curso de Engenharia de Produção em específico foram 532 inscritos com uma relação de candidato vaga de 17.7. Isto indica que a proposta de interiorização está cumprindo seu papel, isto é, oportunizar as minorias o acesso ao Ensino Superior Público.

A Engenharia de Produção preencheu quase a totalidade das vagas anuais ofertadas desde o inicio do CEUNES em 2006. A maior parte dos alunos matriculados é solteira e iniciaram o curso logo após o ensino fundamental, destes $58 \%$ estudaram em escola particular. As famílias dos alunos possuem em média de 4 a 5 pessoas. A renda mensal de $54 \%$ das famílias é superior a 5 salários mínimos, com $85 \%$ das famílias com residências próprias. Além disso, cabe ressaltar que $80 \%$ dos alunos não realizavam atividade remunerada no momento da matrícula.

Outro ponto que merece atenção dentro do perfil dos ingressantes nos cursos é a escolaridade dos pais. Em média $40 \%$ dos pais possuem o ensino médio 
concluído. As mães, por sua vez, apresentaram maior grau de instrução, em média $35 \%$ concluíram o ensino superior. Apesar desta diferença, $80 \%$ dos pais estavam empregados e a taxa de desemprego declarada para as mães foi em média de $30 \%$ de 2009 a 2012.

O curso torna-se mecanismo de mudança no perfil familiar, principalmente, quando se avaliam os motivos que fizeram estes estudantes buscarem o ensino superior: possibilidade de emprego, qualificação para uma profissão e aptidão. É interessante mencionar que maior parte dos alunos da Engenharia de Produção estava mais focada na possibilidade de emprego. Por fim, cabe ressaltar que em média 55\% dos alunos da Engenharia de Produção se declaram brancos, 35\% pardos e $10 \%$ negros.

\section{PERFIL DOS ALUNOS DO CURSO E A RELAÇÃO DE EVASÃo}

No curso de Engenharia de Produção da UFES campus São Mateus entrou 441 alunos entre os anos de 2006 e 2016 de uma possibilidade de 475 vagas ofertadas, ou seja, 93\% de vagas preenchidas ao longo do período, valor este superior ao curso no País que possui média de $70 \%$ de ocupação da vagas ofertadas. Destes a maior parte, 287, foram do sexo masculino. As ingressantes do sexo feminino corresponderam a $35 \%$ do total. Do total de alunos tem-se que mais de $60 \%$ possui entre 17 e 25 anos de idade e que estes apresentam coeficiente de rendimento médio de 6,0 ao longo do curso.

As formas de ingresso ao curso foram: vestibular, SISU (modalidade que começou a ser utilizada em 2016), transferência facultativa, novo curso, remoção e reopção. De todos os alunos a maior parte ingressou por meio do vestibular (390 alunos), seguido pelo SISU (45 alunos), transferência (4 alunos) e novo curso (2 alunos). Por remoção e reopção não foram constatadas nenhuma entrada.

Entre os anos de 2006 a 2008 o número de vagas ofertadas no curso foi de 25 passando a 50 vagas anuais a partir de então. Neste período o número de estudantes ingressantes foi maior que o número de vagas, 26 e 55, devido às formas de ingresso: por transferência e por novo curso. Em 2013 e 2015 o número de entrada foi 32 e 37 estudantes, respectivamente. Cabe ressaltar que nestes anos todos os cursos do CEUNES apresentaram problemas quanto aos processos de 
matrícula, fato este que fez com que fosse trabalhada a entrada pelo SISU. Em 2016 o número de estudantes do sexo feminino foi maior que o sexo masculino (GRÁFICO 3).

Gráfico 3 - Número de alunos matriculados por ano no CEUNES/UFES (2006 a 2016)

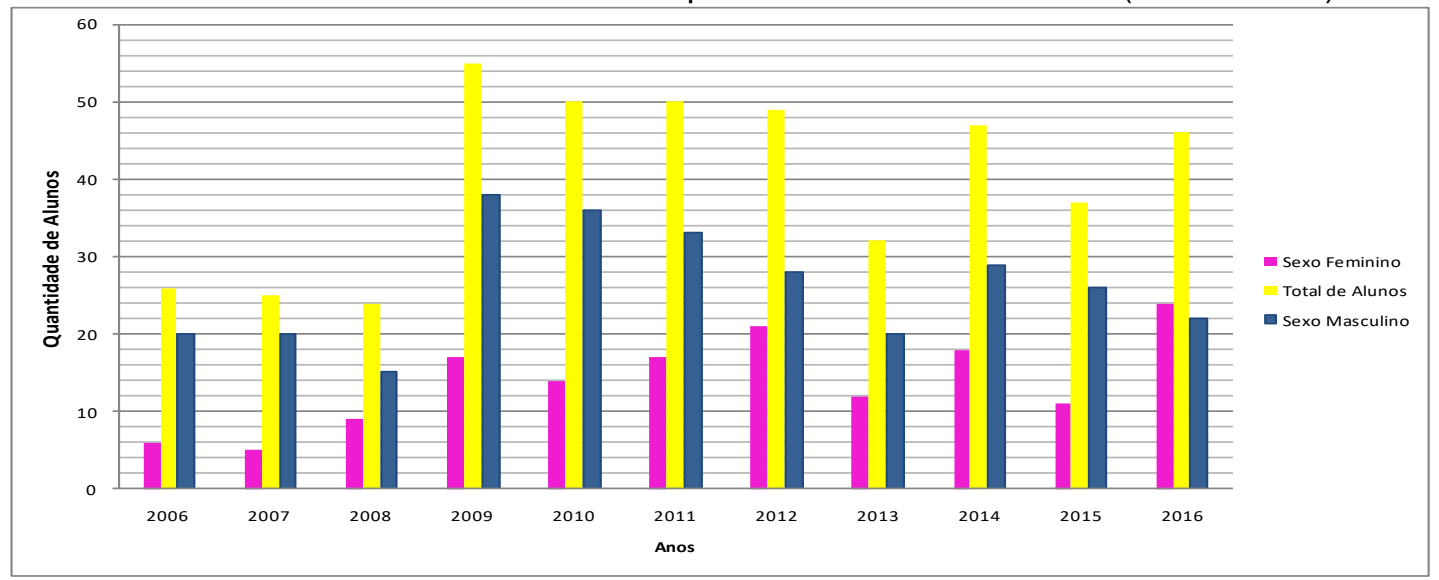

Fonte: Elaborada pelo autor

Quanto ao número de alunos formados entre 2011 e 2015 (GRÁFICO 4) temse o ano de 2014 com o maior número de alunos graduados (27). No período de análise o número médio de alunos formados foi de aproximadamente 18 alunos por ano com desvio padrão igual a 8 . O número de mulheres graduadas foi nulo em 2011, em número constante de 08 alunas em 2012 e 2013 e quase dobrou em 2014 passando a 14. Mas em 2015 apenas 3 alunas concluíram o curso. O número de homens formados teve uma tendência crescente desde 2011, excetuando-se apenas o ano de 2013.

Gráfico 4 - Quantidade de alunos que colaram grau em Engenharia de Produção (2011 a 2015)

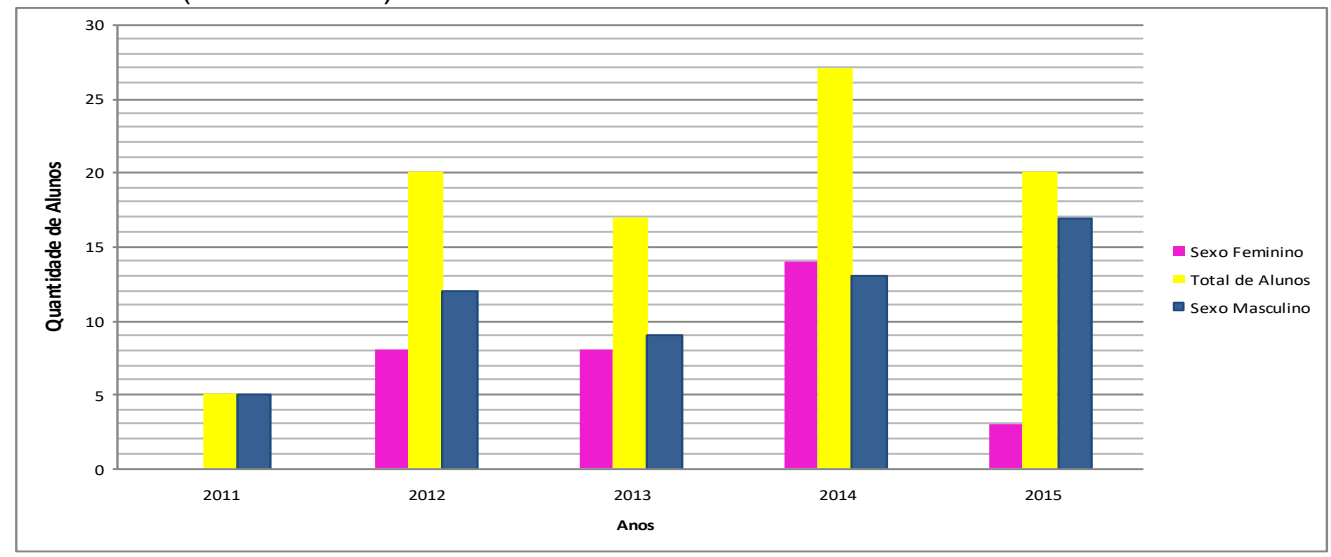

Fonte: Elaborado pelo autor 
Quanto à relação entre o número de alunos concluintes e ingressantes no curso (TABELA 3) pode-se perceber comportamento semelhante ao do Brasil, com o percentual médio de $70 \%$ nos anos de 2012 e 2013 e redução nesta relação para 49\% em 2014 e 44\% em 2015. Para a turma de 2006 a taxa de conclusão do curso foi de $19 \%$, ressalta-se, entretanto que se trata da primeira turma do curso e que a taxa de evasão foi de quase $50 \%$ como será visto posteriormente.

Tabela 3 - Relação entre número de alunos concluintes e número de alunos ingressantes em São Mateus, nos anos de 2011 a 2015

\begin{tabular}{|c|c|c|c|c|}
\hline Ano & Concluintes & Ano & Ingressantes & Percentual Concluintes/Ingressantes \\
\hline $\mathbf{2 0 1 5}$ & 22 & $\mathbf{2 0 1 0}$ & 50 & 0,44 \\
\hline $\mathbf{2 0 1 4}$ & 27 & $\mathbf{2 0 0 9}$ & 55 & 0,49 \\
\hline $\mathbf{2 0 1 3}$ & 17 & $\mathbf{2 0 0 8}$ & 24 & 0,71 \\
\hline $\mathbf{2 0 1 2}$ & 20 & $\mathbf{2 0 0 7}$ & 25 & 0,80 \\
\hline $\mathbf{2 0 1 1}$ & 5 & $\mathbf{2 0 0 6}$ & 26 & 0,19 \\
\hline
\end{tabular}

Fonte: Caderno de avaliação: Engenharia de Produção 35 (UFES, 2013)

O Gráfico 5 mostra os coeficientes de rendimento acumulados (CR) no final do curso pelos alunos concluintes. Os alunos formados em 2011 apresentaram os maiores coeficientes $(7,86)$ podendo ser justificado pelo pequeno número de alunos que colaram grau, apenas 5. Para os demais anos percebe-se tendência de redução do CR.

Gráfico 4 - Coeficiente de rendimento acumulado (CR) de 2011 a 2015, Engenharia de Produção

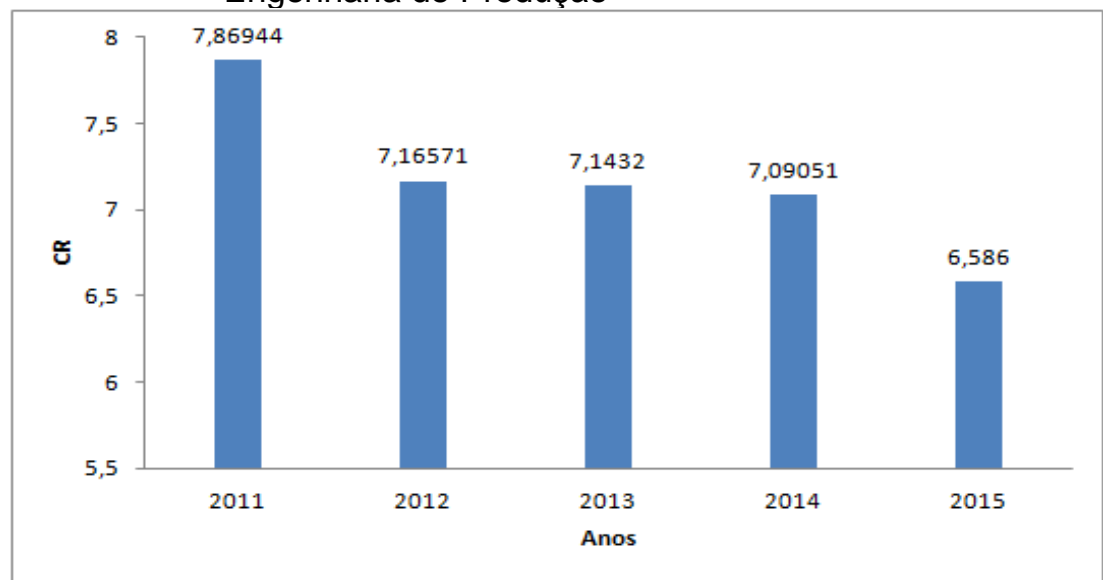

Fonte: Elaborado pelo autor

Apesar do número de alunos que colaram grau no curso, o número de evasão tem aumento muito nos últimos anos. O Gráfico a 06 mostra que nos anos de 2012, 2014 e 2015 ocorreram 28, 26 e 35 evasões por diversos motivos que serão 
discutidos a seguir. Observa-se que houve crescimento ao longo dos anos, principalmente a partir de 2009 quando o número de vagas ofertadas passou a ser 50. Dentre os alunos evadidos, a maioria foi do sexo masculino.

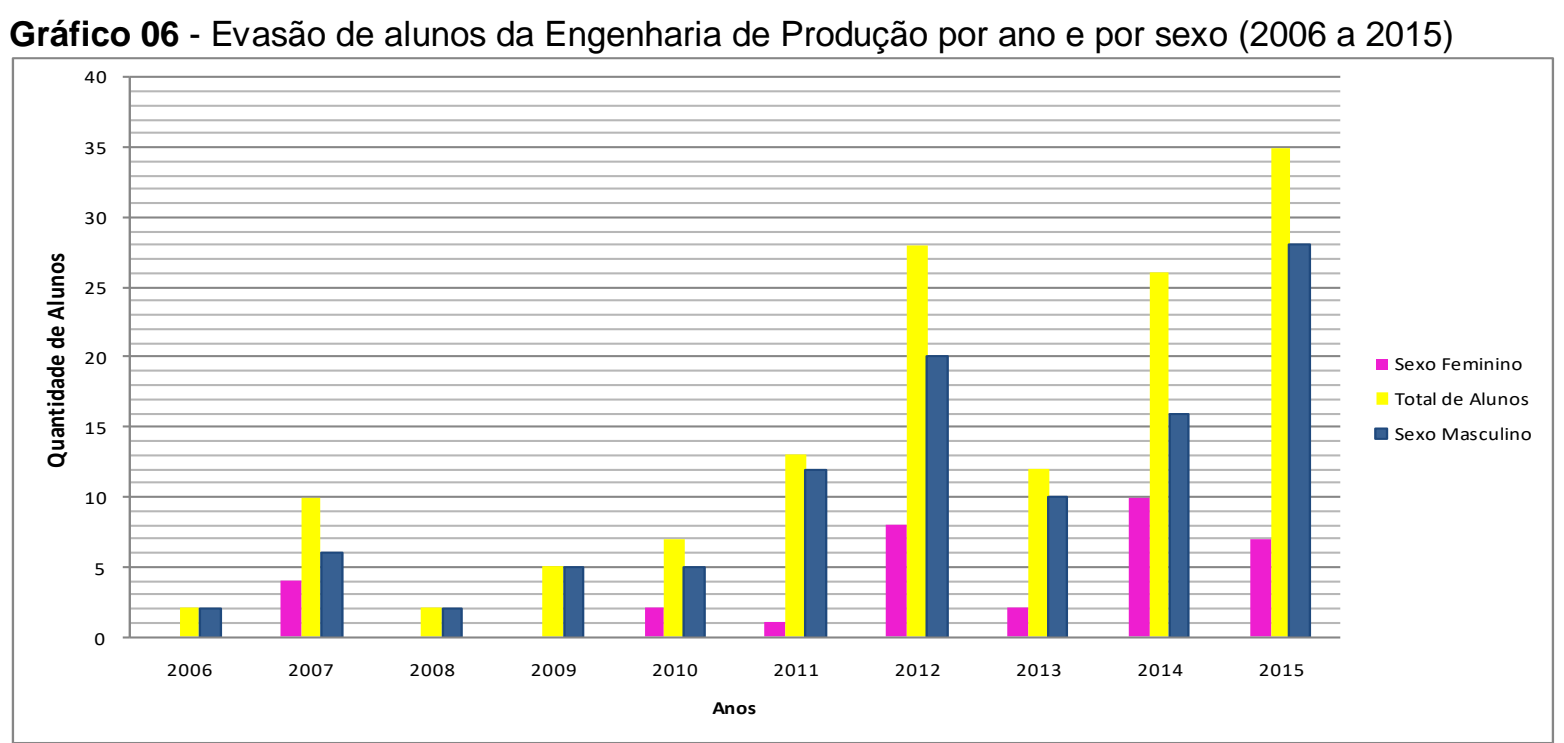

Fonte: Elaborado pelo autor

Ao se comparar o número de alunos matriculados no período de 2010 a 2015 com o número de alunos evadidos tem-se que o percentual de evasão no curso de São Mateus esteve sempre abaixo da média do País que foi de $20 \%$ neste período. O número de matrículas em São Mateus foi de 292 no ano de 2010 e passou para uma média de 380 matrículas entre os anos de 2011 a 2015. Já a taxa de evasão, ou seja, a relação entre o número de alunos evadidos em relação ao número de alunos matriculados foi de 1,7\% em 2010; 3,6\% em 2011; 6,95\% em 2012; 3,15\% em 2013; 8,9\% em 2014 e 9,5\% em 2015. Ao se considerar apenas a evasão em instituições públicas percebe-se que o curso de São Mateus seguiu uma tendência a equalizar com a média do País, uma vez que aumentou gradualmente e atingiu 9,5\% de evasão em relação ao número de matrículas em 2015, próximo a média do país que foi de $10 \%$ ao ano neste mesmo ano.

Considerando agora o número de alunos evadidos em relação ao número de alunos diplomados de 2010 a 2015 (TABELA 4) vê-se que o curso de Engenharia de Produção em São Mateus apresentou índices muito baixos ao longo dos anos demonstrando baixa capacidade de manter o aluno até a sua formatura. Nos anos de 2011, 2012 e 2015 o número de alunos evadidos foi maior que o número de 
alunos diplomados. Ao se comparar a relação diplomados com evadidos com os valores da UFES como um todo se pode perceber que o curso está abaixo dos valores da universidade, mas pode-se ressaltar que nos anos de 2012 e 2015 houve maiores evasões em ambos.

Tabela 4 - Relação alunos diplomados e evadidos no curso de Engenharia de Produção e total de alunos da UFES (2010 a 2015)

\section{Engenharia de Produção}

\section{Anos}

Diplomados \begin{tabular}{|l|l|l|l|l|l|}
2010 & 2011 & 2012 & 2013 & 2014 & 2015 \\
\hline
\end{tabular}

Evadidos 0 5 20

Relação diplomados/evadidos UFES

\begin{tabular}{|l|c|c|c|c|c|c|}
\hline Diplomados & 2.385 & 2.313 & 2.272 & 2.408 & 2.419 & 2.401 \\
\hline Evadidos & 1.307 & 1.135 & 2.710 & 947 & 2.006 & 3.925 \\
\hline Relação diplomados/evadidos & 1,8 & 2,0 & 0,8 & 2,5 & 1,2 & 0,6 \\
\hline
\end{tabular}

Fonte: Indicadores de desempenho (UFES, 2015)

No Gráfico 07 observam-se os tipos de evasão ocorridos no curso de 2006 a 2015. O maior número de evasão foi devido a desistências com 77 alunos, seguido por desligamento por abandono, 41 alunos. Outras formas de evasão ocorreram por desligamento por 3 reprovações em 1 disciplina (13 alunos), reopção de curso (9), desligamento por descumprir plano de estudos e por transferência, ambos com 2 alunos cada.

Gráfico 07 - Tipos de evasão no curso de Engenharia de Produção CEUNES

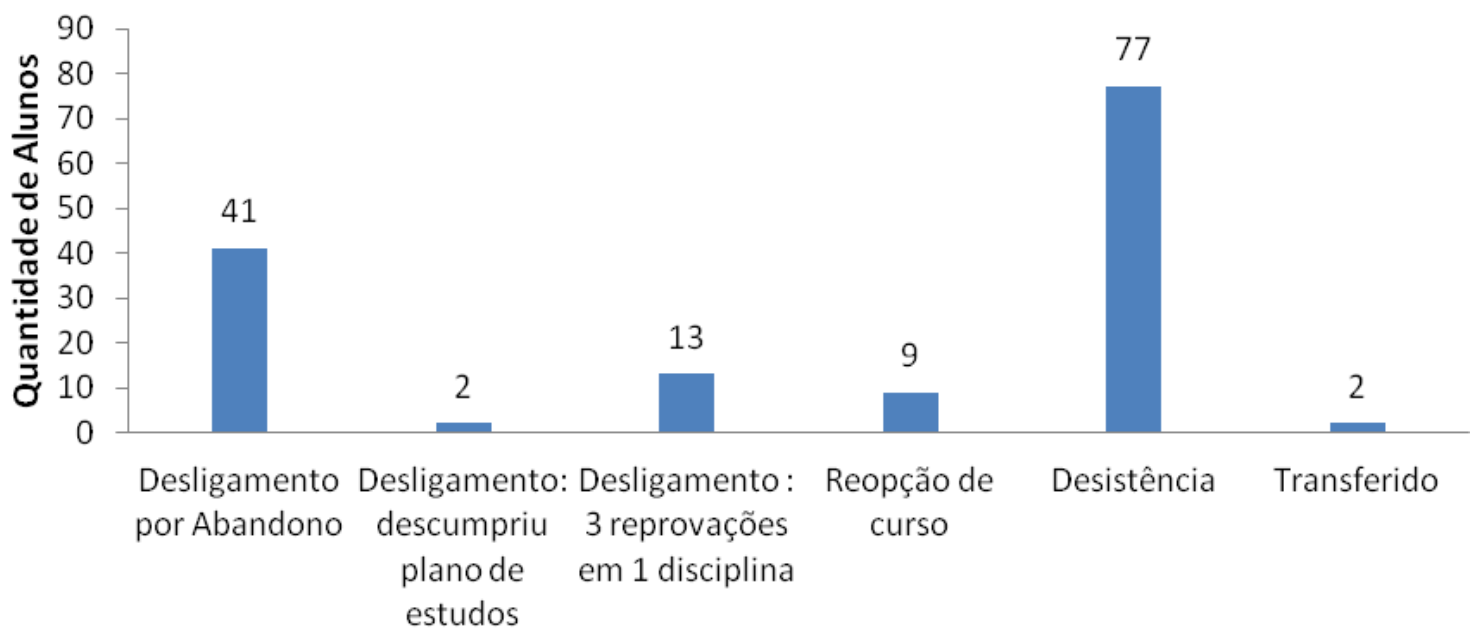

Fonte: Elaborado pelo autor 
Com a finalidade de analisar mais detalhadamente a evasão, foram realizadas análises por cada turma, de 2006 a 2015, por meio do número de alunos evadidos por ano (TABELA 5) e pela quantificação da carga horária no momento da evasão (TABELA 6). Na Tabela 1 observa-se que dos 25 alunos que ingressaram no curso em 2006, 12 evadiram, sendo 2 nos anos de 2006 e 2008 e 6 no segundo ano do curso (2007). O aluno evadido em 2012 possuía 68\% de curso concluído, mas analisando seu histórico pode-se perceber que os 32\% restantes de carga horária era relativa a disciplinas básicas do curso, como cálculos, algoritmos, físicas e etc. Este apresentava número grande de reprovações nestas disciplinas indicando a dificuldade de cumprir as disciplinas básicas do curso.

Para a turma de 2007 a evasão permaneceu no mesmo índice em torno de $50 \%$ dos alunos, pois foi 11 o número de evadidos dos 25 ingressantes. Mais uma vez o maior número de abandono ocorreu nos primeiros anos. Ressalta-se que 04 alunos se matricularam e não iniciaram o curso, pois a carga horária realizada é igual a zero e que a maior parte dos alunos que evadiram não chegaram a concluir nem mesmo 23\% do curso. Para a turma com entrada em 2008 as evasões começaram a ocorrer apenas em 2010 mostrando que os alunos permaneceram mais tempo no curso uma vez que este já se apresentava mais estruturado em termos de infra estrutura (TABELA 5).

\begin{tabular}{|c|c|c|c|c|c|c|c|c|c|c|}
\hline Ane & 2006 & 2007 & 2008 & 2009 & 2010 & 2011 & 2012 & 2013 & 2014 & 2015 \\
\hline 2006 & 2 & & & & & & & & & \\
\hline 2007 & 6 & 4 & & & & & & & & \\
\hline 2008 & 2 & 0 & & & & & & & & \\
\hline 2009 & 1 & 3 & & 1 & & & & & & \\
\hline 2010 & & 1 & 1 & 3 & 2 & & & & & \\
\hline 2011 & 1 & 1 & 3 & 4 & 1 & 3 & & & & \\
\hline 2012 & 1 & 2 & 2 & 7 & 9 & 0 & 7 & & & \\
\hline 2013 & & & & 1 & 1 & 4 & 3 & 3 & & \\
\hline 2014 & & & 2 & 2 & 6 & 6 & 7 & 0 & 3 & \\
\hline 2015 & & & & 4 & 3 & 2 & 9 & 5 & 6 & 6 \\
\hline 2016 & & & & & & & & & 1 & 1 \\
\hline Total & 13 & 11 & 8 & 22 & 22 & 15 & 26 & 8 & 10 & 7 \\
\hline
\end{tabular}

Fonte: Elaborado pelo autor 
A partir da turma de 2009 o curso passou a ter oferta de 50 por vestibular ano. Entretanto, houve entradas de 55, 50, 50, 49, 32, 47 e 37 alunos, respectivamente para os anos de 2009 a 2015. Quanto ao número de alunos evadidos tem-se que a turma de 2012 foi a que apresentou a maior desistência 26 alunos, ou ainda 53\% dos matriculados neste ano. As turmas de 2009, 2010 e 2011 tiveram evasão de $40 \%, 44 \%$ e $30 \%$ dos alunos matriculados, respectivamente. Já as turmas de 2013, 2014 e 2015 apresentam menores evasões em média de 22\% dos matriculados, mas ainda não se pode concluir que estes valores permaneceram ao longo do tempo (TABELA 5).

Quanto ao comportamento de evasões ao longo dos anos, não é possível verificar um padrão comum. Segundo Silva Filho et. al. (2007) a taxa de evasão no primeiro ano de curso é duas a três vezes maiores do que a dos anos seguintes. No entanto isto não ocorre na Engenharia de Produção onde se percebe alto número de evasão no terceiro ou quarto ano de curso. Um fato que pode explicar estes valores está relacionado ao abandono de curso que só pode ser caracterizado após dois semestres consecutivos sem realizar ou trancar a matrícula.

Outro ponto relevante que cabe ser ressaltado aqui é que os alunos quando percebem que estão com possibilidade de serem desligados do curso, ou com CR muito baixo ou ainda por possibilidade de participarem do programa Ciências sem Fronteira acabaram por realizar o vestibular novamente para obterem novo número de matrícula. Com estas características tem-se 01 aluno que evadiu em 2011 com retorno em 2016; 02 alunos evadidos em 2012 vestibular em 2013 e para os anos de 2013, 2014 e 2015 foram 03 evasões em cada ano com reingresso em ano subseqüente.

Estes fatos podem ser visualizados na Tabela 6 onde mostra a carga horária realizada pelos alunos no momento da evasão. De 2006 até 2011 a carga horária está abaixo de 30\% da carga horária obrigatória do curso, mas a partir de 2012 esta média aumenta. Exemplo seria a turma de 2010 no ano de 2013 em que a média da carga horária realizada foi de $54 \%$ do total do curso. 
Tabela 6 - Carga horária realizada no momento da evasão por turma de entrada na Engenharia de Produção (2006 a 2015)

\begin{tabular}{|c|c|c|c|c|c|c|c|c|c|c|}
\hline Ane & 2006 & 2007 & 2008 & 2009 & 2010 & 2011 & 2012 & 2013 & 2014 & 2015 \\
\hline 2006 & $\overline{0}$ & & & & & & & & & \\
\hline 2007 & 612,5 & 0 & & & & & & & & \\
\hline 2008 & 870 & 0 & & & & & & & & \\
\hline 2009 & 0 & 940 & & 0 & & & & & & \\
\hline 2010 & & 195 & 1365 & 675 & 367,5 & & & & & \\
\hline 2011 & & 120 & 625 & 0 & 0 & 555 & & & & \\
\hline 2012 & 2775 & 810 & 457,5 & 955 & 487,5 & 0 & 345 & & & \\
\hline 2013 & & & & & 2190 & 918,75 & 652,5 & 600 & & \\
\hline 2014 & & & 2565 & 1897,5 & 1010 & 462,5 & 830 & 0 & 45 & \\
\hline 2015 & & & & & 810 & 1477,5 & 613,13 & 1500 & 532,5 & 945 \\
\hline 2016 & & & & & & & & & 210 & 765 \\
\hline
\end{tabular}

Fonte: Elaborado pelo autor

Quanto aos alunos que estão devidamente matriculados tinha-se total de 208 em 2016. Das turmas de 2006 e 2007 não há mais alunos em curso. Da turma de 2008 há um aluno com carga horária realizada de 4085 e coeficiente de rendimento de 7,21. Este aluno está apto a colar grau e provavelmente o fará após 08 anos de curso. Da turma de 2009 há 4 alunos sem evasão, com média de carga horária de 4457,75 e desvio padrão de 359,07. A média do coeficiente de rendimento destes alunos é 6,10 com desvio padrão de 0,325. Todos estes alunos provavelmente estarão colando grau até o fim deste ano, pois estão na dependência da apresentação de trabalho de conclusão de curso.

Para a turma de 2010 ainda estão matriculados 13 alunos, sendo que 09 deles possuem condições de colar grau em 2016/01. Ressalta-se que entre estes alunos 05 participaram do programa Ciências sem Fronteira permanecendo de um a um ano e meio fora do país. A média de coeficiente de rendimento destes alunos é de 6,95. A turma de 2011, por sua vez, possui 32 alunos, sendo que deste total 13 possuem possibilidade de colar grau em 2016/01. Dos 19 alunos restantes considera-se que concluíram o curso dentro de um ano, pois falta completar 15,30\% da carga horária em média (TABELA 7). 
Tabela 7 - Número de alunos matriculados, média de carga horária e coeficiente de rendimento, bem como os desvios padrão por turmas

\begin{tabular}{ccccccc}
\hline & $\mathbf{2 0 1 0}$ & $\mathbf{2 0 1 1}$ & $\mathbf{2 0 1 2}$ & $\mathbf{2 0 1 3}$ & $\mathbf{2 0 1 4}$ & $\mathbf{2 0 1 5}$ \\
\hline Alun oS & 13 & 32 & 22 & 24 & 37 & 30 \\
\hline $\mathbf{C H}$ & 3718 & 3418 & 2306,6 & 1913,12 & 1418,75 & 677,67 \\
$\boldsymbol{\sigma}_{\mathrm{CH}}$ & 208,41 & 549 & 665,2 & 490,4 & 852,9 & 340,32 \\
$\mathbf{C R}$ & 6,95 & 7,15 & 6,19 & 6,35 & 5,9 & 5,56 \\
$\boldsymbol{\sigma}_{\mathrm{CR}}$ & 0,987 & 0,82 & 0,95 & 0,9 & 1,55 & 1,81 \\
\hline
\end{tabular}

$\mathrm{CH}=$ Carga horária realizada; $\sigma \mathrm{cH}$ desvio padrão da carga horária realizada; $\mathrm{CR}=$ Coeficiente de Rendimento; $\sigma_{C R}$ desvio padrão do Coeficiente de Rendimento.

Fonte: Elaborado pelo autor

A turma de 2012 possui previsão de formatura para o segundo semestre de 2016 e o banco de dados da UFES ainda não fornece o número provável de alunos para conclusão do curso para esta turma. No entanto, analisando a média de carga horária pode-se inferir que a maior parte dos alunos não estarão aptos a colarem grau no tempo devido, mas sim a partir de 2017. Ressalta-se ainda que esta turma obteve coeficiente de rendimento menor que as turmas de 2010 e 2011 e que apresentou o maior número de alunos evadidos do curso no período analisado, 26 alunos (TABELA 5).

As turmas de 2013 e 2015 tiveram número de matrículas percentualmente menores que as demais anos, sendo 32 e 37 alunos respectivamente. Mas ao analisar o percentual de alunos que permanecem no curso das turmas de 2013, 2014 e 2015 tem-se que 75\%, 78,8\% e 81,1\% dos alunos ainda estão devidamente matriculados, respectivamente. Outro ponto que chama atenção é quanto ao coeficiente de rendimento médio dos alunos que é baixo no inicio do curso isto devido à grande dificuldade que os alunos possuem em completar o ciclo básico da engenharia (TABELA 7).

Torna-se importante para complementar a análise da evasão do curso relacionar este fator ao número de alunos retidos e a questão das reprovações ao longo do curso. Considerando o número de alunos matriculados, número de alunos retidos e a taxa de retenção (TABELA 8) vê-se que o curso de Engenharia de Produção apresentou índice de 8,9\%, 7,6\%, 8,6\% e 15,3\% nos anos de 2012 a 2015 consecutivamente. Este índice mostra a relação dos alunos que já deveriam estar formados e ainda estão entre os alunos matriculados. Comparado aos valores do mesmo índice aplicado a UFES como um todo, pode-se dizer que a Engenharia de 
Produção está com uma taxa baixa, mas deve melhorar reduzindo estes valores. Para este indicador quanto menor a taxa maior é a capacidade do curso em fazer com que seus alunos formem dentro do tempo adequado.

Tabela 8 - Número de alunos matriculados, alunos retidos e a taxa de retenção no curso de Engenharia de Produção e UFES (2012 a 2015)

\section{Engenharia de Produção}

\section{Matriculados}

Retidos

Taxa de retenção

UFES

Matriculados

Retidos

Taxa de retenção

Fonte: Indicadores de desempenho (UFES, 2015)

\section{Anos}

\begin{tabular}{|c|c|c|c|}
\hline $\mathbf{2 0 1 2}$ & $\mathbf{2 0 1 3}$ & $\mathbf{2 0 1 4}$ & $\mathbf{2 0 1 5}$ \\
\hline 190 & 184 & 174 & 176 \\
\hline 17 & 14 & 15 & 27 \\
\hline 8,9 & 7,6 & 8,6 & 15,3 \\
\hline
\end{tabular}

\begin{tabular}{|l|l|l|l|l}
18.199 & 18.331 & 18.271 & 18.720 \\
\hline
\end{tabular}

\begin{tabular}{|l|l|l|l|l|}
\hline 2.589 & 2.923 & 3.219 & 3.667 \\
\hline
\end{tabular}

\begin{tabular}{l|l|l|r|}
\hline 14,2 & 15,9 & 17,6 & 19,6 \\
\hline
\end{tabular}

Associado a taxa de retenção pode ser analisado ainda o tempo médio de conclusão do curso de modo a determinar o tempo de retenção. $O$ tempo médio de conclusão de curso para a Engenharia de Produção foi de 10 semestres para 2011; 10,8 semestres para 2012; 11,6; 11,2 e 12,6 semestres para 2013, 2014 e 2015 consecutivamente. A média de 2010 a 2015 foi de 11,5 semestres. Considerando que o tempo sugerido para conclusão do curso é de 10 semestres tem-se o tempo de retenção é igual há 1,5 semestres (UFES, 2015).

De acordo com a revisão de literatura o número de alunos evadidos possui uma relação direta com o número de reprovações. O curso de Engenharia de Produção apresentou em 2008, 497 matrículas com 175 reprovações, ou seja, um percentual de reprovação de $35,2 \%$. Para o ano de 2011 o número de matrículas foi de 1.710 para 392 reprovações, ou seja, 22,9\% (UFES, 2013).

De modo a relacionar as reprovações com os valores de retenção foi feita uma análise do número de alunos matriculados e retidos por disciplina. Ao tabular o dado percebeu-se que as disciplina com maior índice de retenção são as disciplinas de primeiro e segundo períodos. As disciplinas do terceiro e quarto período ainda aparecem com um número significativo de reprovações, no entanto, menores que os períodos anteriores. As disciplinas profissionalizantes a partir do quinto período apresentam taxas de retenção menores que 10\% na maior parte das vezes. 
Considerando o elevado grau de retenção das disciplinas dos dois primeiros períodos do curso fez-se uma análise mais detalhada das mesmas. Os Gráficos 08 e 09 mostram o grau de retenção de cada disciplina. No primeiro período (GRÁFICO 08) os alunos de São Mateus cursam Metodologia da Pesquisa, Introdução a Engenharia de Produção, Gestão da Qualidade Total, Geometria Analítica, Química Geral I, Programação I e Cálculo I.

As disciplinas de Metodologia da Pesquisa, Introdução a Engenharia de Produção, Gestão da Qualidade Total apresentaram ao longo do tempo taxas de retenção menores a 15\%, exceção para o ano de 2012 em que a taxa de retenção foi à maior de todo o curso para todas as disciplinas. Ressalta-se que a turma de 2012 é a turma com maior número de alunos evadidos no total de 26 , e que a taxa de retenção nas disciplinas de Química Geral I e Cálculo I foi próxima a 80\%, ultrapassando este valor para a última disciplina citada (GRÁFICO 08).

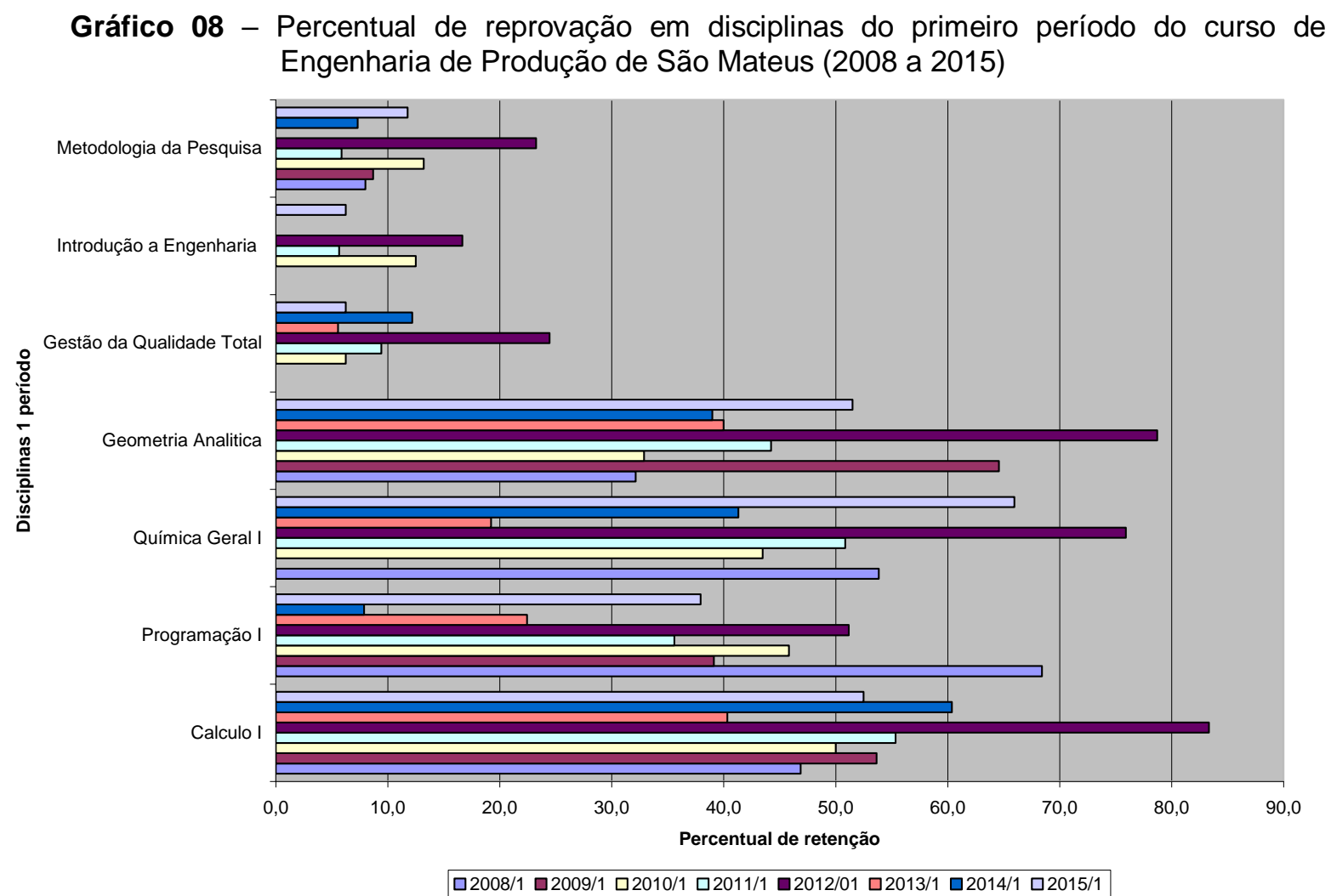

De um modo geral as disciplinas de Geometria Analítica, Química Geral I, Programação I e Cálculo I, apresentaram taxas de retenção acima de 40\% para todos os anos analisados (GRÁFICO 08). Os dados da evasão nos mostraram que 
os alunos não evadem no primeiro período, mas que o fazem ao longo de mais anos. Uma razão discutida anteriormente está associada ao fato dos alunos desistirem do curso e não solicitarem o seu desligamento, sendo este realizado após dois semestres consecutivos sem matrícula pela própria UFES. No entanto, tem-se que considerar ainda que os alunos acabem por cursar as disciplinas básicas por duas, três ou mais vezes até terem a certeza de que não conseguiram realizá-las e acabam por desistir do curso.

Quando analisadas as disciplinas do segundo semestre do curso: Diagnóstico de Processos Produtivos I, Teoria Geral da Administração (TGA), Desenho Técnico, Álgebra Linear, Cálculo II, Fundamentos de Mecânica Clássica e Programação II, têm-se comportamento semelhante às disciplinas do primeiro período, onde as disciplinas de Diagnóstico de Processos Produtivos I, Teoria Geral da Administração (TGA), Desenho Técnico, aprecem com taxas de retenção abaixo de $20 \%$, cabendo as disciplinas Álgebra Linear, Cálculo II, Fundamentos de Mecânica Clássica e Programação II maiores taxas de retenção (GRÁFICO 09).

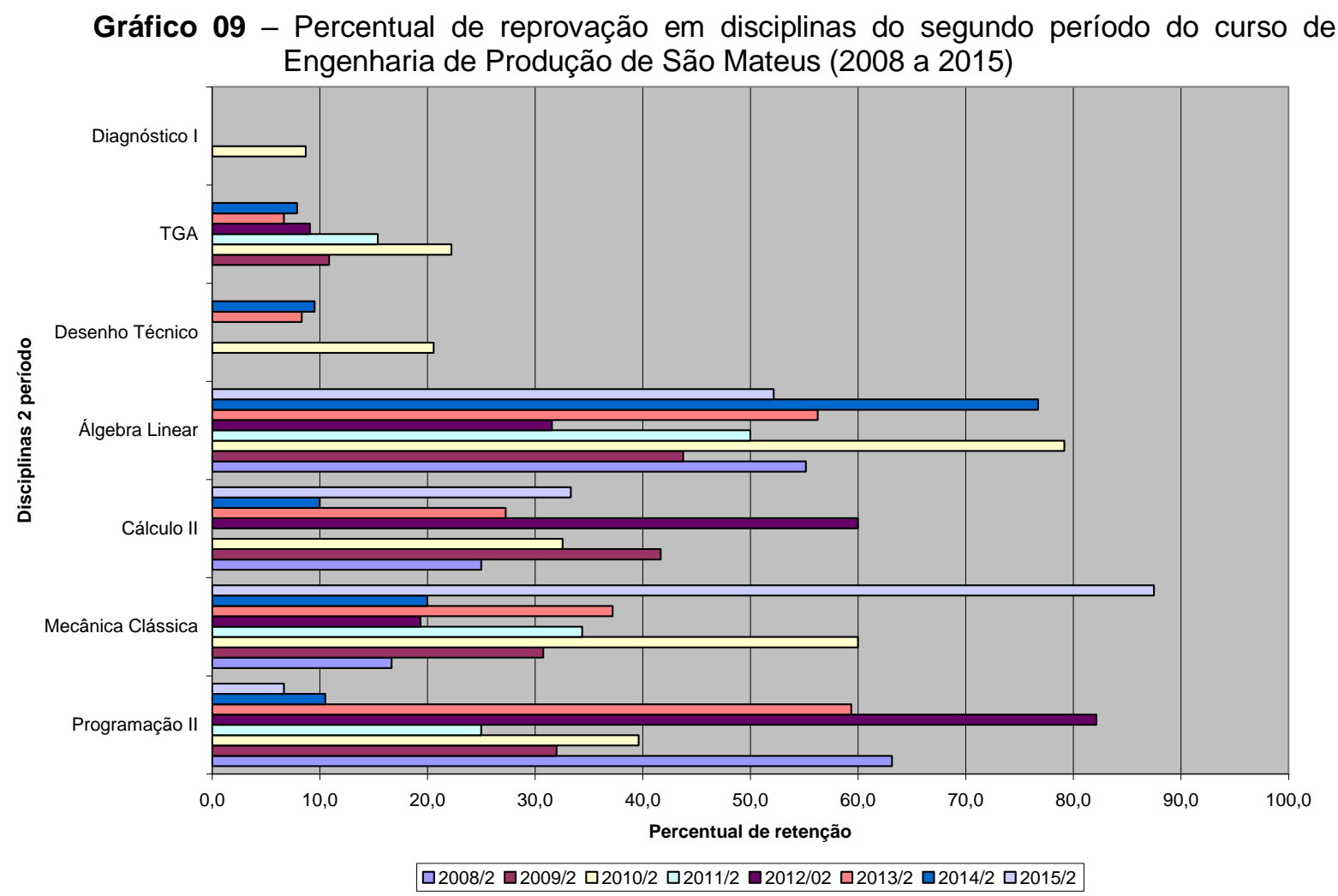




\section{CONSIDERAÇÕES FINAIS}

Este estudo teve como objetivo levantar algumas características no Curso de Engenharia de Produção, campus São Mateus, bem como as causas da evasão das turmas no período de 2006 a 2016. Verificou-se que o curso possui $65 \%$ dos alunos do sexo masculino e $80 \%$ do total de alunos são naturais do próprio Estado. No vestibular de 2016, 50\% dos matriculados eram da própria cidade de São Mateus. Além disso, cabe ressaltar que a maior parte dos alunos é jovem com dedicação exclusiva aos estudos e família com renda superior a 05 salários.

Quanto ao rendimento acadêmico dos alunos percebe-se que o mesmo melhora à medida que os mesmos vão concluindo as disciplinas do ciclo básico e partindo para as disciplinas específicas passando de 5,56 em 2015 para média de 6,95 em 2010. Pode-se perceber isto até mesmo analisando o CR dos alunos que colaram grau.

O curso apresentou no período analisado uma média de 18 alunos formados por ano com elevado desvio padrão (igual a 8) associado a uma taxa de evasão pequena quando comparada a taxa nacional e tendência a igualar a taxa para instituições públicas no País. Ressalta-se que 77 alunos do curso evadiram por desistência. Associado a estes valores tem-se ainda que o curso apresentou um número pequeno de alunos diplomado em relação ao número de alunos evadidos indicando a baixa capacidade do curso de fazer com que os alunos finalizem a graduação. Quando a taxa de retenção esta pode ser reduzida melhorando o tempo de conclusão do curso, ou seja, mesmo os alunos que estão colando grau estão concluindo o curso em tempo maior o determinado pelo projeto pedagógico do curso.

De modo a relacionar a evasão com a retenção foi realizada uma análise da quantidade de alunos retidos por disciplinas no curso. Verificou-se que as disciplinas do primeiro e segundo períodos possuem maior número de retenção, seguido do terceiro e quarto período. As disciplinas profissionalizantes que ocorrem a partir do quinto período e mesmo em períodos iniciais apresentaram retenções menores.

As disciplinas de Geometria Analítica, Química Geral I, Programação I, Cálculo I, Álgebra Linear, Cálculo II, Fundamentos de Mecânica Clássica e Programação II apresentaram elevados valores de retenção, de $40 \%$ a $80 \%$ do 
número de alunos matriculados. Estes valores vêm a corroborar a hipótese que a desistência dos alunos possa estar relacionada à falta de preparo para cursar as disciplinas básicas e que realmente existe uma grande deficiência nas disciplinas de matemática e física.

A evasão é indicativa de falhas no processo de ensino e ineficácia do serviço prestado. Além do aumento de gastos financeiros, pois a mesma estrutura acadêmica que deveria atender determinado grupo inicial estaria sendo destinada a um quantitativo menor de alunos. Desta maneira, há de se buscar ações que visem minimizar a evasão dos alunos no curso. Não existe uma fórmula, mas algumas estratégias tem se mostrado eficazes neste sentido. Assim segue algumas sugestões com vistas à redução dos índices da evasão para a coordenação do curso:

- Falta de conexão com o curso: muitos alunos chegam ao curso sem saber exatamente o que um engenheiro de produção pode realizar. Desta forma, uma orientação vocacional no inicio do curso, bem como atividades de divulgação dos cursos nas escolas seria benéfico. Esta atividade poderá dar retornos uma vez que grande parte dos alunos é da própria região;

- Melhorar o rendimento acadêmico: como foram diagnosticados e corroborados por outros trabalhos os alunos estão apresentando dificuldades de aprendizado devido à falta de conhecimento básico em disciplinas como: matemática, física e português. Desta forma, cursos de nivelamento, monitorias, vídeo aulas e tutorias podem mudar 0 destino do aluno que teria possibilidade de evadir;

- Dificuldades financeiras: mostrar aos alunos as políticas assistências existentes na Universidade; bem como a possibilidade de bolsas acadêmicas para trabalhos de ensino, pesquisa e extensão.

Outros fatores que podem contribuir para a evasão dos alunos no curso de Engenharia de Produção no CEUNES/UFES podem estar relacionados à insatisfação com qualidade de ensino, com o corpo docente ou com a infraestrutura. Estas questões não foram quantificadas neste trabalho, mas podem ser visualizadas no caderno de avaliação do curso (UFES, 2013). Nesta pesquisa, realizada junto a 
209 alunos matriculados no primeiro período de 2012 é nítido a insatisfação dos alunos quanto aos pontos citados.

Quanto à infra estrutura do CEUNES em relação ao curso de Engenharia de Produção mais $50 \%$ dos alunos considera de regular a ruim: laboratórios, internet, vias de acesso e segurança no campus. Já quanto ao aos aspectos didáticos pedagógicos, a maior parte dos pontos foram classificados pelos alunos de bom a regular, destaca-se: conteúdo e organização disciplinar, utilização de tecnologias no ensino, carga horária total do curso e sua distribuição ao longo dos semestres. No entanto, para os alunos a falta de regularidade de oferta em disciplinas obrigatórias e optativas é um agravante. Outro ponto que chama atenção está relacionado ao número de docentes e sua capacidade de exercer a função que segundo os alunos foi classificado de bom a regular.

Desta forma, o problema da evasão no ensino superior está associado a uma gama de fatores que deve ser trabalhado pelo professores, coordenadores e gestão da Universidade. É um problema que envolve desde a falta de preparo dos alunos, questões pessoais de ordem econômicas e psicológicas até mesmo a infra estrutura da instituição e o seu corpo docente.

\section{REFERÊNCIAS}

ADACHI, Ana Amélia Chaves Teixeira. Evasão e Evadidos nos Cursos de Graduação da Universidade Federal de Minas Gerais. Universidade Federal de Minas Gerais Faculdade de Educação Programa de Pós-Graduação em Educação. Belo Horizonte, 2009.

FERREIRA, Joaquim Armando; ALMEIDA, Leandro; SOARES, Ana Paula. Adaptação acadêmica em estudante do $1^{\circ}$ ano: diferenças de gênero, situação de estudante e curso.. Psico-USF, v.6, n.1, p. 01-10. jan./jun. 2001.

GAIOSO, Natalícia Pacheco de Lacerda. O fenômeno da evasão escolar na educação superior no Brasil. Dissertação (Mestrado em Educação) - Programa de Pós-Graduação em Educação da Universidade Católica de Brasília. Brasília, 2005.

GILIOLI, Renato de Sousa Porto. Evasão em instituições federais de ensino superior no Brasil: expansão da rede, Sisu e desafios. Estudo técnico, 2016. http://www2.camara.leg.br/documentos-e-pesquisa/publicacoes/estnottec/areas-daconle/tema11/2016_7371_evasao-em-instituicoes-de-ensino-superior_renato-gilioli

GOMES, Maria José; MONTEIRO, Mariana; DAMASCENO, Anderson Medeiros; ALMEIDA, Tereza Jacy Silva; DE CARVALHO, Raquel Baroni. Evasão acadêmica no ensino superior: estudo na área da saúde. Revista Brasileira de Pesquisa em Saúde, v. 12, n. 1, p. 6-13, 2010. 
INSTITUTO NACIONAL DE ESTUDOS E PESQUISAS EDUCACIONAIS ANÍSIO TEIXEIRA (INEP) e Conselho Federal de Engenharia e Agronomia (CONFEA) (Brasília). Trajetória e estado da arte da formação em engenharia, arquitetura e agronomia. 2010. Disponível em: http://www.ufff.br/observatorioengenharia/files/2012/01/vol07.pdf. Acesso em: 08 de janeiro de 2016.

INSTITUTO NACIONAL DE ESTUDOS E PESQUISAS EDUCACIONAIS ANÍSIO TEIXEIRA - INEP (Brasília). Estatísticas da educação superior: graduação, 2016.

http://portal.inep.gov.br/web/guest/sinopses-estatisticas-da-educacao-superior

LOBO, Maria Beatriz de Carvalho Melo. Panorama da evasão no ensino superior brasileiro: aspectos gerais das causas e soluções. Associação Brasileira de Mantenedoras de Ensino Superior. Cadernos, n. 25, 2012.

MARTINS, Tatiane Agostinho; BITENCOURT, Lígia Cristina; BARBOSA, Milena de Lima; DOS SANTOS, Leonice Roque. Avaliação das condicionantes de retenção dos alunos de engenharia da UTFPR: bases para propostas interventivas. Cuarta conferencia Latino Americana sobre el abano en la educacion superior, 2014. Obtido em WWW://clabes2014alfaguia.org.pa/ em janeiro de 2017.

OLIVEIRA, Vanderli Fava de; BARBOSA, Carolina dos Santos; CHRISPIM, Eduardo Mathiasi. Cursos de engenharia de produção no Brasil: crescimento e projeções. XXV ENCONTRO NACIONAL DE ENGENHARIA DE PRODUÇÃO, 25., 2005. Anais... Porto Alegre, RS, Brasil, 2005.

OLIVEIRA, Vanderlí Fava; DE ALMEIDA, Nival Nunes, CARVALHO, Dayane Maximiano de; PEREIRA, Fernando Antonio Azevedo. Um estudo sobre a expansão na formação em engenharia no Brasil. Revista de ensino de engenharia. Revista de Ensino de Engenharia da ABENGE, v. 32, p. 29-44, 2013

PEREIRA, Alexandre Severino; CARNEIRO, Teresa Cristina Janes; BRASIL, Gutemberg Hespanha; CORASSA, Maria Auxiliadora de Carvalho. Principais características dos alunos retidos dos cursos de graduação presencial da Universidade Federal do Espírito Santo.

Revista GUAL, Florianópolis, v. 9, n. 2, p. 238-259, maio 2016.

UNIVERSIDADE FEDERAL DO ESPÍRITO SANTO - UFES. Caderno de avaliação:

Engenharia de Produção 35. Centro Universitário Norte do Espírito Santo. Vitória, 2013.

UNIVERSIDADE FEDERAL DO ESPÍRITO SANTO - UFES. Indicadores de desempenho, 2015. Pro Reitoria de Planejamento e Desenvolvimento Institucional. Vitória, 2015.

SILVA FILHO, Roberto Leal Lobo; MOTEJUNAS, Paulo Roberto; HIPÓLITO, Oscar; MELO LOBO, Maria Beatriz de Carvalho. A Evasão no ensino superior brasileiro: instituto lobo para o desenvolvimento da educação, da ciência e da tecnologia. Cadernos de Pesquisa. v. 37. n. 132, 2007.

SILVA, Glauco Peres. Análise de evasão no ensino superior: uma proposta de diagnóstico de seus determinantes. Avaliação, v. 18, n. 2, p. 311-333, jul. 2013,

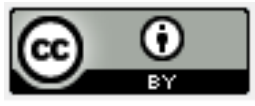

Artigo recebido em 02/03/2017 e aceito para publicação em 18/04/2017

DOI: http://dx.doi.org/10.14488/1676-1901.v17i3.2760 